Virginia Commonwealth University

VCU Scholars Compass

Biology Publications

Dept. of Biology

2004

\title{
The effect of loading on disturbance sounds of the Atlantic croaker Micropogonius undulatus: Air versus water
}

\author{
Michael L. Fine \\ Virginia Commonwealth University, mfine@vcu.edu \\ Justin Schrinel \\ Virginia Commonwealth University \\ Timothy M. Cameron \\ Virginia Commonwealth University
}

Follow this and additional works at: http://scholarscompass.vcu.edu/biol_pubs

Part of the Acoustics, Dynamics, and Controls Commons, Biology Commons, and the Marine Biology Commons

Copyright (2004) Acoustical Society of America. This article may be downloaded for personal use only. Any other use requires prior permission of the author and the Acoustical Society of America. The following article appeared in J.

Acoust. Soc. Am. 116, 1271 (2004) and may be found at http://dx.doi.org/10.1121/1.1736271.

\section{Downloaded from}

http://scholarscompass.vcu.edu/biol_pubs/18

This Article is brought to you for free and open access by the Dept. of Biology at VCU Scholars Compass. It has been accepted for inclusion in Biology

Publications by an authorized administrator of VCU Scholars Compass. For more information, please contact libcompass@vcu.edu. 


\title{
The effect of loading on disturbance sounds of the Atlantic croaker Micropogonius undulatus: Air versus water
}

\author{
Michael L. Fine ${ }^{\mathrm{a})}$ and Justin Schrinel \\ Department of Biology, Virginia Commonwealth University, Richmond, Virginia 23284-2012 \\ Timothy M. Cameron \\ Department of Mechanical Engineering, Virginia Commonwealth University, \\ Richmond, Virginia 23284-3015
}

(Received 4 December 2003; revised 3 March 2004; accepted 6 March 2004)

\begin{abstract}
Physiological work on fish sound production may require exposure of the swimbladder to air, which will change its loading (radiation mass and resistance) and could affect parameters of emitted sounds. This issue was examined in Atlantic croaker Micropogonius chromis by recording sounds from the same individuals in air and water. Although sonograms appear relatively similar in both cases, pulse duration is longer because of decreased damping, and sharpness of tuning ( $\mathrm{Q}$ factor) is higher in water. However, pulse repetition rate and dominant frequency are unaffected. With appropriate caution it is suggested that sounds recorded in air can provide a useful tool in understanding the function of various swimbladder adaptations and provide reasonable approximation of natural sounds. Further, they provide an avenue for experimentally manipulating the sonic system, which can reveal details of its function not available from intact fish underwater. (C) 2004 Acoustical Society of America. [DOI: 10.1121/1.1736271]
\end{abstract}

PACS numbers: 43.80.Ka, 43.80.Lb [WA]

Pages: $1271-1275$

\section{INTRODUCTION}

The acoustics of swimbladders is of interest in diverse fields including acoustic communication (hearing and sound production) in fishes, sonar and deep scattering layers both in terms of fishery investigations and military applications. Classically, the swimbladder has been modeled as a pulsating underwater bubble (Bergeijk, 1964; Harris, 1964), an omnidirectional, resonant monopole that is vibrated by incident sound and then radiates near-field vibrations to the ears or scatters sound back to sonar receivers. Underwater studies have demonstrated that swimbladders have a lower Q, an index of sharpness of tuning, and are more rapidly damped than a free bubble (Batzler and Pickwell, 1970; McCartney and Stubbs, 1970; Sand and Hawkins, 1973; Weston, 1967), but this difference is typically explained as a consequence of damping by fish tissue rather than a property of the bladder. Weston (1967) demonstrated that a bladder's shape can alter its natural frequency, and more modern studies employing boundary element modeling have considered bladder shape as a variable (Francis and Foote, 2003). These models, however, do not consider the possibility that the bladder for other reasons may not act as a resonant bubble.

Recent work on toadfish and weakfish is not in agreement with the classical conceptions of swimbladder acoustics; their bladders appear to be low Q resonators (Bradbury and Vehrencamp, 1998) that gain little amplitude from resonance. Deflating the swimbladder does not affect hearing thresholds in the toadfish or in several other hearing generalist species (Fay and Popper, 1975; Lugli et al., 2003; Yan et al., 2000), and the directionality pattern of toadfish boatwhistles measured in the York River departs from omnidirec-

a)Electronic mail: mlfine@vcu.edu tionality, in a pattern reflecting the heart shape of the swimbladder (Barimo and Fine, 1998). Physiological work comparing sound emission to bladder movement patterns measured with a laser vibrometer in air indicated motion resembling more a lateral quadrupole than a monopole (Fine et al., 2001) although the bladder has a monopole component that dominates the radiation because of its small size compared to a wavelength of emitted sound (Barimo and Fine, 1998). Finally, the damping coefficient of the bladder in air is equivalent to that of an automobile shock absorber, not what would be expected of a resonant bubble (Fine et al., 2001).

Similarly in weakfish, dominant frequency appears to be related to contraction parameters of the sonic muscle rather than the natural frequency of the bladder (Connaughton et al., 2000, 2002). Different cycles of the pulse waveform vary in duration, and the inverse of the second cycle, the one with the greatest energy, closely predicts the dominant frequency of the call. Its duration increases in larger fish, which would take longer to complete a muscle twitch, resulting in a lower dominant frequency. Furthermore, in similarly sized fish its duration decreases at higher temperatures, which would permit a more rapid twitch, resulting in a higher dominant frequency. Neither of these findings is consistent with sound generation by the natural frequency of the bladder.

The weakfish were recorded in air to escape the difficulties inherent in small tanks including resonance and proximity to pressure release boundaries (Akamatsu et al., 2002; Parvulescu, 1964), and the ventral surface of the toadfish swimbladder was exposed to air as the target in the laser vibrometer study. This exposure to air reduces the mass loading and radiation resistance on the bladder and indicates that body damping does not account for our failure to observe resonance effects. Reducing the mass and resistance loading decouples them from other loads and allows analysis of other 
acoustic characteristics such as damping of the swimbladder wall. Because access to the bladder in air provides numerous advantages for acoustical and physiological investigations, it is important to experimentally determine the affect of changes in loading (air versus water) on fish swimbladder sounds. We examined this problem during an investigation of sounds in Atlantic croaker Micropogonius chromis by recording sounds from a series of fish in both air and water (each fish was compared against itself in both conditions).

\section{METHODS}

Croakers Micropogonius undulatus were caught in the Chesapeake Bay and maintained in running York River water in a tank at the Oyster Hatchery at the Virginia Institute of Marine Science. Individuals were netted and transported in a bucket with aeration to the adjacent boat harbor for recording. The harbor is enclosed except for a narrow passageway and is typically free of wave and boat engine noise. Each fish was recorded in air with a microphone while being hand held for several seconds. It was then quickly placed in a plastic mesh holder and immediately suspended to a depth of $0.75 \mathrm{~m}$ (water depth was $1.5 \mathrm{~m}$ ) at a distance of $1 \mathrm{~m}$ from a Sippican calibrated omnidirectional hydrophone, also at $0.75-\mathrm{m}$ depth. The hydrophone and fish were both positioned $1 \mathrm{~m}$ from a horizontal walkway, i.e., they were approximately $2 \mathrm{~m}$ from the wooden wall of the harbor. Some fish required gentle prodding with a dowel rod to induce sound production. Sounds were recorded on a Sony TCD model digital audio tape recorder (48 kHz bandwidth) and analyzed on a Kay Elemetrics 5500 Sonagraph. Typically five pulses per individual were analyzed although two of the fish in water produced fewer than five pulses in which case all pulses were measured (one fish produced three pulses and another four). The data for each fish were averaged and treated as an $N$ of 1. We recorded sounds in both air and water for five fish and compared them by paired $t$-test. Because train duration and number of pulses were not normally distributed, they were compared with a Mann-Whitney U test.

\section{RESULTS}

Croaker disturbance call trains are longer in air than in water $[p=0.008$, Fig. 1(a) $]$. In fact some fish that call when being handled in air lapse into silence upon return to the water or produce fewer pulses $[p=0.03$, Fig. 1(b)], suggesting that being handled in air is perceived as a greater disturbance than being confined and prodded underwater.

Croaker calls appear generally similar on sonagrams whether recorded in air or water (Fig. 2) although expanded oscillograms indicate important differences (Fig. 3). Oscillograms of individual pulses start with a low amplitude half cycle that can be either positive or negative but is negative in these recordings. In water the next cycle has the greatest amplitude and contains most of the energy in the call followed by a rapid decay [Fig. 3(d)]. The major difference between waveforms in air and water is the decay pattern, which damps more rapidly in air. Coincident with greater damping, the power spectrum is broader and less peaked in air although central frequencies are similar in both spectra
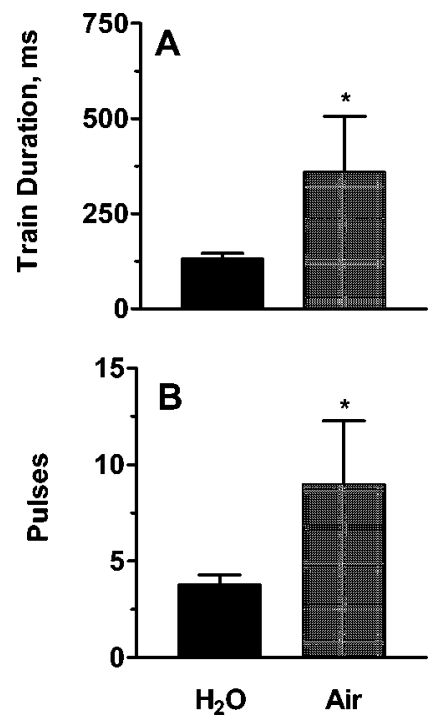

FIG. 1. Mean $\pm S E$ train duration (a) and number of pulses per train (b) for five croakers recorded in water and air.

(Fig. 3). Dominant frequencies and durations of the most intense cycle are also similar in air and water [Figs. 4(a) and (d)], and the duration of the most intense cycle largely determines the dominant frequency. Similarly, the pulse repetition rate was similar in both conditions [Fig. 4(f)]. Significant differences exist in the sharpness of tuning, and $\mathrm{Q}$ values approximately double from a mean of 1.3 to 2.9 [Fig. 4(b)], a factor of 2.2 sharper in water. Values for individuals range from 1.04 to 1.48 in air and from 2.08 to 3.09 in water. Again the increased sharpness is reflected in more rapid damping in air, with water sounds having a longer duration [Fig. 4(c)] and averaging an extra cycle [Fig. 4(e)].
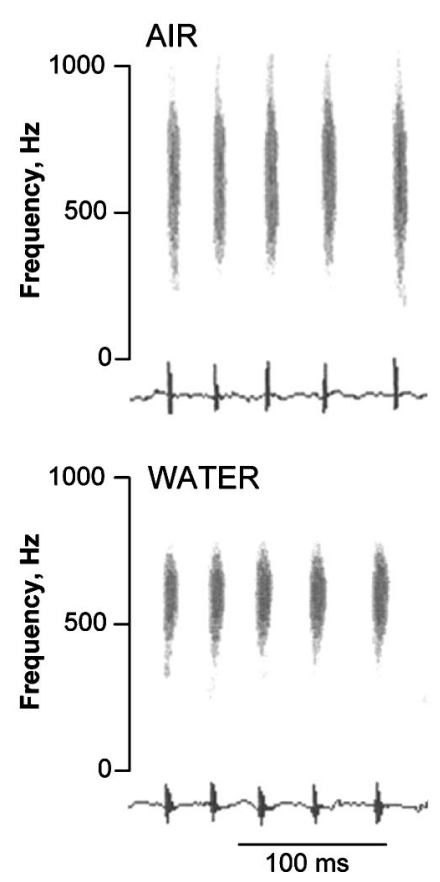

FIG. 2. Sonagram and oscillogram of a train of sounds recorded in air and under water from an individual croaker. 


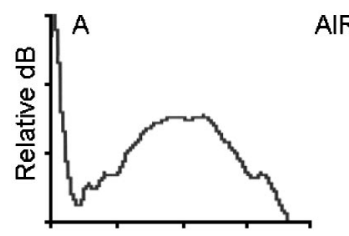

AIR

C
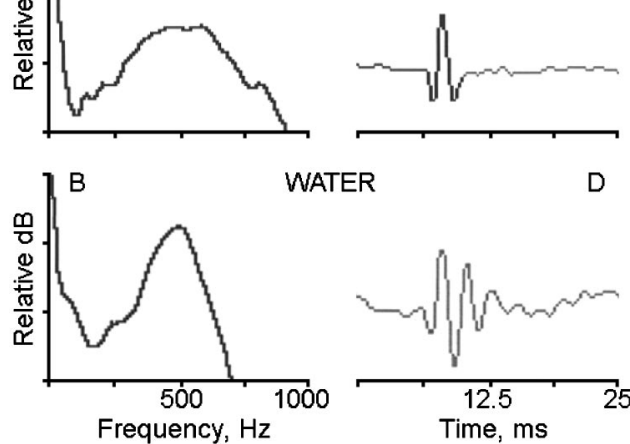

WATER

D

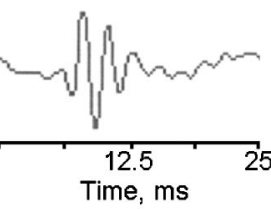

FIG. 3. Expanded oscillograms and power spectra of a sound pulse recorded in water and air from the individual in Fig. 2. Tick marks on the relative $\mathrm{dB}$ scale represent $7 \mathrm{~dB}$

\section{DISCUSSION}

Examining the physiology and acoustics of sonic muscle-swimbladder mechanisms in sound production in air provides numerous advantages, particularly accessibility and simplified acoustics, compared to recording sounds in natural bodies of water, typically at unknown distances from the caller, or in tanks that are subject to various artifacts (Akamatsu et al., 2002; Parvulescu, 1964). Further, some fish disturbance calls may actually be directed against aerial predators (Fine and Ladich, 2003), and sounds recorded in air and water generally appear qualitatively similar on sonagrams.

An important question is the effect of reflections from the harbor wall and the surface on the call waveforms. We discount wall reflections as important since pine has a similar acoustic impedance to sea water $\left(1.57 \times 10^{6}\right.$ to $1.54 \times 10^{6}$
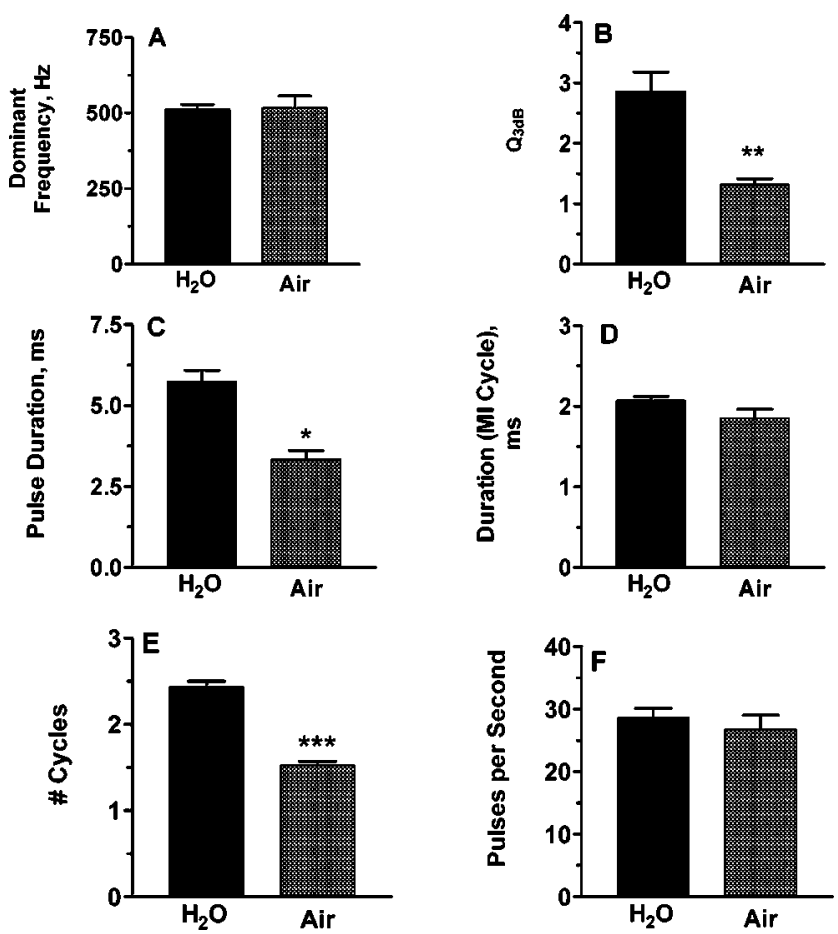

FIG. 4. Comparison of sound parameters (mean $+\mathrm{SE})$ recorded in water and air for five croakers. Statistics are based on paired $t$-tests. ${ }^{*} p<0.05, * * p$ $<0.01, * * * p<0.001$.
TABLE I. Determination of $k \cdot a$; validation of low frequency approximation.

\begin{tabular}{|c|c|c|}
\hline Parameter & Water@ $95 \mathrm{~cm}$ & Air \\
\hline Static pressure, $P\left(\right.$ dynes $\left./ \mathrm{cm}^{2}\right)$ & $1.088 \times 10^{6}$ & $1.013 \times 10^{6}$ \\
\hline Density, $\rho\left(\mathrm{g} / \mathrm{cm}^{3}\right)$ & 1.025 & $1.21 \times 10^{-3}$ \\
\hline Speed of sound, $c(\mathrm{~cm} / \mathrm{s})$ & $1.5 \times 10^{5}$ & $3.4 \times 10^{4}$ \\
\hline Dominant oscillation frequency, $f(\mathrm{~Hz})$ & 500 & 500 \\
\hline Wave number, $k=2 \pi \mathrm{f} / \mathrm{c}(\mathrm{rad} / \mathrm{cm})$ & 0.0209 & 0.0924 \\
\hline Croaker swimbladder radius, $a(\mathrm{~cm})$ & 2.0 & $2.048^{\mathrm{a}}$ \\
\hline$k \cdot a$ & 0.042 & 0.189 \\
\hline Radiation mass $^{\mathrm{b}}(\mathrm{g})$ & 103 & 0.131 \\
\hline Radiation resistance $^{\mathrm{b}}$ (dyne $\cdot \mathrm{s} / \mathrm{cm}$ ) & $1.36 \times 10^{4}$ & 77.7 \\
\hline
\end{tabular}

${ }^{a}$ The swimbladder radius in air is calculated from the radius in water using Boyle's Law (for the same moles of gas at the same temperature: pressure $\times$ volume $=$ constant $)$.

${ }^{\mathrm{b}}$ Kinsler et al. (2000), Eq. (8.10.24): $m_{r}=4 \pi a^{3} \rho$ and $R_{r}=4 \pi a^{2} \rho c(k a)^{2}$.

Rayls, respectively) (Kinsler et al., 2000), and saturation with water would diminish even this small difference. Wet soil grading to dry behind the sea wall will also not offer a sharp discontinuity. The air-water interface is a strong reflective barrier, but it will reflect a signal out of phase, making it unlikely that a longer signal, i.e., lower damping, is an artifact of reflection. Additionally the hydrophone and fish were positioned half way between the surface and the bottom, which will reflect a signal in phase. Opposite phases of reflections from the surface and bottom should ensure at least some measure of cancellation of these extraneous signals. In any event a true free acoustic field without reverberation from barriers and living organisms does not occur in the shallow waters in which croakers live. Our calculations (Table I) indicate that the mass loading of a 2-cm-radius bubble (approximate dimension of the croaker swimbladder) in water at $0.75 \mathrm{~m}$ depth is almost 1000 times greater than the mass loading in air, and the radiation resistance is 175 times greater in water. Reflections do not change the signal frequency, so loading effects are the only factor in considering the possibility of changes in resonant frequency. The large loading differences will have a much greater effect on the damping comparison than the artifacts of reflections.

The current investigation makes it clear that there is a price incurred for the decreased mass and resistance loading in air, but we suggest that price may not be as great as it first appears. Pulse repetition rate for croaker sounds is similar between air and water. Since pulse repetition rate is determined by a central nervous system pattern generator, the basic neural control of sound production appears unchanged. Further, driving patterns of the swimbladder forced by sonic muscle contraction should be unchanged as indicated by the similarity in duration of the most intense cycle of the call, which has been shown to determine the dominant frequency of weakfish (Connaughton et al., 2000, 2002) and croaker calls (Schrinel et al., in progress). Muscle origin, insertion and action will not change in air, and the bladder will be vibrated in a similar pattern and frequency. The radiation pattern can be affected by changing " $k \cdot a$," where " $k$ " is the wave number and " $a$ " is the characteristic radius of the source, but in both air and water the low frequency limit approximation for $k \cdot a \ll 1$ holds fairly well (Table I).

We suggest that the differences in these calls recorded in 
air and water would not be particularly meaningful to the fish. Fishes primarily rely on the temporal structure of their calls for coding information (Fine et al., 1977; Winn, 1964; Zelick et al., 1999), and pulse rate does not change though pulse duration does. This difference in pulse duration would likely be at least partially masked by other fish signals and background noise in a chorus of calling fish. These signals were recorded under unusually quiet conditions, and measuring the duration of fish pulses recorded in natural bodies of water is notoriously difficult because it is almost impossible to determine precisely when a call disappears in the background noise. Therefore the final attenuated cycle in water is less likely to be heard unless the fish are close to each other. Although the frequency spectra are broader in air than in water, the dominant frequencies are similar. Since dominant frequency scales inversely with fish size in weakfish (Connaughton et al., 2000, 2002) and croaker (Schrinel et al. in progress), it is reasonable to hypothesize that croakers could estimate relative size of the caller equally in aerial and underwater recordings. Frequency discrimination thresholds to tones measured in hearing generalist fishes are likely to be over $50 \mathrm{~Hz}$ for a $500-\mathrm{Hz}$ tone and increase at higher frequencies (Fay and Megela Simmons, 1999). To our knowledge perception of differences in frequency spectra for pulsatile sounds has not been measured in fishes. The amplitude of the sound in the tails of the broader frequency spectrum is less than the amplitude surrounding the dominant frequency, and the more intense dominant frequency would tend to mask concurrent sound of lower amplitude (Fay and Megela Simmons, 1999). There is currently no basis to presume the fish would detect sound in the weaker tails of the distribution (the ability to discriminate frequencies degrades at higher frequencies, and lower frequencies are more likely to be masked by additional background noise).

Differences between air and water affect the related parameters of pulse duration, bladder damping and sharpness of tuning. The bladder experiences a forced rather than a resonant response from the sonic muscles since the dominant frequency is the same in both media. If the response were driven by a bladder resonance, the dramatic reduction in mass loading in air would increase the dominant frequency (Fine et al., 2001; Kinsler et al., 2000). However, the broader frequency peak in air suggests that the response of the bladder is not fully controlled by muscle contractions. The broader peak in air suggests that muscle contraction is a one-way actuator that drives the dominant frequency of the response, at least for the first quarter cycle, and perhaps longer, but that the swimbladder relaxes according to a free response controlled by its mechanical properties (mass, stiffness, damping) and the radiation mass and resistance loading.

A complete understanding of fish swimbladders as acoustic radiators must consider acoustic loading in their natural habitats. However, opening the inside of fishes to companion anatomical, physiological and acoustical study including measurements made in air will provide a deeper understanding of various bladder adaptations and their acoustic functions. Considering potential artifacts from tank recordings (Akamatsu et al., 2002) and effects of back- ground noise and environmental filtering in field recordings of unseen subjects (Fine and Lenhardt, 1983; Lugli and Fine, 2003; Mann and Lobel, 1997), aerial recordings provide a reasonable approximation of natural sounds. The duration of short sounds like weakfish and croaker pulses driven by a single muscle contraction represent the worst case, whereas effects on longer sounds such as a toadfish boatwhistle will be minimal in aerial recordings.

\section{ACKNOWLEDGMENTS}

We thank James McConnell of Acoustech Corporation for criticizing the mansuscript, Willy Reay of the Institute for Coastal and Estuarine Environmental Technology for help obtaining fish and logistical help, and Stan Allen for providing tank space at the oyster hatchery at the Virginia Institute of Marine Science. These experiments comply with the Principles of animal care, publication No. 86-23, revised 1985 of the National Institute of Health. Work was supported by a grant from the Virginia Marine Resources Commission. Contribution No. 2592 from the Virginia Institute of Marine Science.

Akamatsu, T., Okumura, T., Novarini, N., and Yan, H. Y. (2002). "Empirical refinements applicable to the recording of fish sounds in small tanks," J. Acoust. Soc. Am. 112, 3073-3082.

Barimo, J. F., and Fine, M. L. (1998). "Relationship of swim-bladder shape to the directionality pattern of underwater sound in the oyster toadfish," Can. J. Zool. 76, 134-143.

Batzler, W. E., and Pickwell, G. V. (1970). "Resonant acoustic scattering from gas-bladder fishes," in Proceedings of an International Symposium on Biological Sound Scattering in the Ocean, edited by G. B. Farquhar (U.S. Government Printing Office, Washington, DC), pp. 168-179.

Bergeijk, W. A. v. (1964). "Directional and nondirectional hearing in fish," in Marine Bioacoustics, edited by W. N. Tavolga (Pergamon, New York), pp. 281-299.

Bradbury, J. W., and Vehrencamp, S. L. (1998). Principles of Animal Communication (Sinauer, Massachusetts).

Connaughton, M. A., Fine, M. L., and Taylor, M. H. (2002). "Weakfish sonic muscle: influence of size, temperature and season," J. Exp. Biol. 205, 2183-2188.

Connaughton, M. A., Taylor, M. H., and Fine, M. L. (2000). "Effects of fish size and temperature on weakfish disturbance calls: implications for the mechanism of sound generation," J. Exp. Biol. 203, 1503-1512.

Fay, R. R., and Megela Simmons, A. (1999). "The sense of hearing in fishes and amphibians," in Comparative Hearing: Fish and Amphibians, edited by R. R. Fay and A. N. Popper (Springer, New York), pp. 269-318.

Fay, R. R., and Popper, A. N. (1975). "Modes of stimulation of the teleost ear," J. Exp. Biol. 62, 379-387.

Fine, M. L., and Ladich, F. (2003). "Sound production, spine locking and related adaptations," in Catfishes, edited by B. G. Kapoor, G. Arratia, M. Chardon, and M. Diogo (Oxford and IBH, New Delhi), pp. 249-290.

Fine, M. L., and Lenhardt, M. L. (1983). "Shallow-water propagation of the toadfish mating call," Comp. Biochem. Physiol. 76A, 225-231.

Fine, M. L., Winn, H. E., and Olla, B. L. (1977). "Communication in fishes," in How Animals Communicate, edited by T. A. Sebeok (Indiana U.P., Bloomington), pp. 472-518.

Fine, M. L., Malloy, K. L., King, C. B., Mitchell, S. L., and Cameron, T. M. (2001). "Movement and sound generation by the toadfish swimbladder," J. Comp. Physiol., A 187, 371-379.

Francis, D. T., and Foote, K. G. (2003). "Depth dependent target strengths of gadoids by the boundary-element method," J. Acoust. Soc. Am. 114, 3136-3146.

Harris, G. G. (1964). "Considerations on the physics of sound production by fishes," in Marine Bio-acoustics, edited by W. N. Tavolga (Pergamon, New York), pp. 233-247.

Kinsler, L. E., Frey, A. R., Coppens, A. B., and Sanders J. V. (2000). Fundamentals of Acoustics, 4th ed. (Wiley, New York). 
Lugli, M., and Fine, M. L. (2003). "Acoustic communication in two freshwater gobies: Ambient noise and short-range propagation in shallow streams," J. Acoust. Soc. Am. 114, 512-521.

Lugli, M., Yan, H. Y., and Fine, M. L. (2003). "Acoustic communication in two freshwater gobies: the relationship between ambient noise, hearing and sound spectrum," J. Comp. Physiol., A 189, 309-320.

Mann, D. A., and Lobel, P. S. (1997). "Propagation of damselfish (Pomacentridae) courtship sounds," J. Acoust. Soc. Am. 101, 3783-3791.

McCartney, B. S., and Stubbs, A. R. (1970). "Measurement of the target strength of fish in dorsal aspect, including swimbladder reonance," in Proceedings of an International Symposium on Biological Sound Scattering in the Ocean, edited by G. B. Farquhar (U.S. Government Printing Office, Washington, DC), pp. 180-211.

Parvulescu, A. (1964). "Problems of propagation and processing," in $\mathrm{Ma}$ rine Bio-acoustics, edited by W. N. Tavolga (Pergamon, New York), pp. $87-100$.
Sand, O., and Hawkins, A. D. (1973). "Acoustic properties of the cod swimbladder,” J. Exp. Biol. 58, 797-820.

Weston, D. E. (1967). "Sound propagation in the presence of bladder fish," in Underwater Acoustics, vol 2, edited by V. M. Albers (Plenum, New York), pp. 55-88.

Winn, H. E. (1964). "The biological significance of fish sounds," in Marine Bioacoustics, edited by W. N. Tavolga (Pergamon, New York), pp. 213231.

Yan, H. Y., Fine, M. L., Horn, N. S., and Colon, W. E. (2000). "Variability in the role of the gasbladder in fish audition," J. Comp. Physiol., A 187, 371-379.

Zelick, R., Mann, D. A., and Popper, A. N. (1999). "Acoustic communication in fishes and frogs," in Comparative Hearing: Fish and Amphibians, edited by R. R. Fay and A. N. Popper (Springer, New York), pp. 363-411. 